The Fifth Scientific Conference of Obour Institutes

"Engineering and Informatics for Sustainable Smart Organizations "

\title{
The Impact of Digital Transformation on Internal Audit
}

\author{
Dr. Haassan Radwan ${ }^{1}$, Ahmed Zeidan ${ }^{2,}$ Haitham Elbasuony ${ }^{3}$ \\ ${ }^{1}$ Lecturer at Al-Obour Higher Institute for Management and Informatics \\ hasanradwan@oi.edu.eg \\ ${ }^{2}$ Lecturer at Al-Obour Higher Institute for Management and Informatics \\ azedian@oi.edu.eg \\ ${ }^{3}$ Lecturer at Al-Obour Higher Institute for Management and Informatics \\ helbasuony@oi.edu.eg
}

\begin{abstract}
The advancement of computer and information technologies has created a favourable external environment for the teaching of English. There are far more than 300 million English learners worldwide. Information technology offers them with a wealth of English teaching materials, as well as the potential for instructors to modify their educational techniques in order to increase teaching and learning efficiency. This article examines how to modify educational techniques for teachers to enhance teaching efficiency and enable students to grasp English as a second language quickly and effectively, as well as the use and benefits of e-learning in English teaching.
\end{abstract}

Keywords: Digital transformation, Internal Audit.

\section{Introduction}

As the world is experiencing at the present time an excellent technological development and quick moving towards digital transformation, many governments have started changing to what is called Electronic Government "E-Government" to gain the benefit of such technology which could summarized, reducing the human mistakes, quality, accuracy and effectiveness in performing work, also reduce time consuming.

In addition to the Educational, institutions have become highly dependent on information technology to support the delivery of personalized material, digital content, interactive classes, and others. These

Institutions are progressively transitioning into Cloud Computing technology (Fernando.et.al 2012)

Accordingly, the Egyptian government during these days is investing lot of effort, time and money to change to E-Government, including internal audit departments.

The world today is moving rapidly towards digital transformation, as result it is imposing itself on professional fields such as accounting and auditing, as well as internal auditing, so the profession needs to be developed with progress of the surrounding environment.

\section{Important:}

-Scientific important:

The profession success of internal audit departments depends on always keeping in track with digital transformation and modern developments in business, which need high attention to technical aspects. This create important of how such changes will affect the internal audit, as the achieving of internal audit professional goals needs quick and effort of all level of 
workers to be familiar with the development and adjust their methods of work accordingly.

\section{-Practical "field work" important}

Also as mentioned by, Internal Audit Foundation and Audit Board, 202, internal audit is considered a cost center in most organizations and constantly has to justify investments: "Most companies first think about transforming revenue generating services, then the services that have cross-enterprise impact, and internal audit may be last.

Accordingly, the internal audit may face a problem of justifying their cost for the stakeholder.

\section{The Main Objective:}

The aim of this study is to get result of how the digital transforming is affecting the internal audit.

\section{Design and methodology:}

The researcher has use deductive methodology by conducted a review of the literature survey to find out the Impact of digital transformation on internal audit

\section{The Assumptions:}

The study is based on tow assumptions:

-There is an impact of the digital transformation on internal audit

-There is no impact of the digital transformation on internal audit

\section{Digital Transformation:}

\section{Definition}

There is a different between "digitisation" and "digitalisation" when describing the use of technologies. Digitisation refers to "the technical process of converting analog signals into a digital form, and ultimately into binary digits", whereas digitalisation is "the process of introducing digital technologies, which essentially deal with changes caused by information technologies" (Bettim Nathanaël and Gerrit Sarens, 2021),

As a result, Digital Transformation may define as "the use of new digital technologies (social media, mobile, analytics or embedded devices) to enable major business improvements (such as enhancing customer experience, streamlining operations or creating new business models)". The innovation is about "combinations of information, computing, communication, and connectivity technologies". This means the process of digital transformation is accompanied by information system use. Further: the strategy and not only the technology is in focus. (LiereNetheler, et.al. 2018),

Law:

The study of (Nambisana S.,et.al. 2019), has mentioned that the introduction of Digitization has also compelled government agencies and other public institutions to rethink the laws, regulations, and policies related to a wide range of issues including intellectual property rights data privacy and security, consumer rights, worker skills and training, entrepreneurial financing and securities, incubator/accelerator programs, and regional/local economic development.
Danger:

The dangers resulting from new digital technologies are driven by five main trends "PWC":

1. Digital disruption: Technologies such as mobile platforms, data analytics, social media, the cloud, and the Internet of Things have been disrupting business models across sectors.

2. Business and technology transformation: Evolving business models, the consumerisation of IT, and the massive transformation of applications and infrastructure have put some businesses on unfamiliar footings.

3. Big data: Huge increases in transaction volume, data volume, and data quality have increased the need for better data governance and management.

4. Cyber security and privacy risks: Cyber risksincluding the theft of customer data and intellectual property, denial-of-service attacks, and cyber espionage - have become clear and present dangers to the global business ecosystem.

5. Regulatory pressure: An emerging web of global regulation focused on privacy, cyber security, resilience, and critical technology platforms has been adding complexity for companies across industries.

\section{Costs}

The digital transformation leads to reduce cost through using cloud computing which means the process of Maintenance, Storage, Management, Processing, Analytics, and Security of data by exploiting a network of Internet-based servers. Data is not saved on physical devices, but in the cloud, this helps businesses to better manage the administration, to streamline processes, improve productivity, optimize costs and enhance customer digital experience. IDC (2018)

\section{Previous studies:}

1- Portzenheim, (2019), "The impact of digital transformation on the internal audit process and practices"

The study suggests that there is an impact of the digital transformation of organizations on the internal audit process and practices. It implies a further evolution in the internal auditors' role. They can now offer a higher level of assurance with less effort, enabling them to better assume their consulting role. Furthermore, the scope of consulting activities will soon be broadened, with an additional focus on the future.

-Nathanaël Betti and Gerrit Sarens, (2021),'Understanding the internal audit function in a digitalised business environment":

The analysis reveals that a digitalized business environment affects the internal audit function in three respects. First, it impacts its scope. The agility of the internal audit planning and the required digital knowledge are expected to increase and information technology (IT) risks gain importance, especially cyber security threats. Second, the demand for consulting activities performed by internal auditors is higher and 
third, digitalization modifies the working practices of internal auditors in their day-to-day tasks.

New technologies such as data analytics tools are being implemented progressively in internal audit departments and digital skills are considered a critical asset.

-Mohamed Mousa, (2020)," Measuring the impact of activating the internal audit activities for digital transformation mechanisms to enhance accountability and transparency and improve the governmental performance: With a field evidence in the Egyptian environment"

It was concluded that the comprehensive risk-based internal audit plan should include procedures and policies for examining the DT strategy and checking the rate of technological development and digital technologies used within government institutions and their various applications, and adopting a variety of ideas and experiences to assess the risks that are associated by implementing these technologies via digital platforms and websites, and the internal audit plays an effective consultative role to drive digital value by identifying the risks specific to the organization and providing strategic advice and valueadded services About it. Finally, the results of the field survey revealed the existence of significant relationships between each of: (the nature and scope of the internal audit activities, and areas of examination that can be practiced to verify the efficiency and effectiveness of the strategies for implementing the DT, and the components of activating these activities in light of the requirements of the ruling professional standards and publications, and the nature of challenges and risks associated with the implementation of DT strategies in the Egyptian environment), and between the tasks of the internal audit function in the field of digital transformation. The results also revealed a significant impact between activating the internal audit activities for the DT mechanisms and enhancing accountability and transparency and improving the governmental performance in the Egyptian environment.

Nayar, K.B. and Kumar, V. (2018) 'Cost benefit analysis of cloud computing in education'Application of cloud computing in education not only relieves the educational institutions from the burden of handling the complex IT infrastructure management as well as maintenance activities, but also leads to huge cost savings. Along with many industry sectors, education sector would be largely benefited by adopting cloud services. Cloud promises to deliver affordable, reliable and flexible computing solutions to the education sector and enable it to compete more effectively with bigger organizations.

- Fernando Koch, Marcos D. Assun c̃ao, Marco A. S. Netto,(2012)" A Cost Analysis of Cloud Computing for Education"
Educational institutions have become highly dependent on information technology to support the delivery of personalized material, digital content, interactive classes, and others. These institutions are progressively transitioning into Cloud Computing technology to shift costs from locally hosted services to a "renting model" often with higher availability, elasticity, and resilience. Moreover, there is an opportunity for both educational institutions and Cloud providers to collaborate in order to enhance the quality of services and reduce costs..

\section{Results}

From the above, we conclude the followings:

1-There is a need for new regulations and law to govern the digital transformation to secure and protect the users.

2-There is a great impact of digital transformation on internal audit in many ways such as "Chartered Institute of Internal Audit, Sept. 2020":

a. Internal Audit planning: they should consider collaboration, connectivity and communication

b. Audit Skills: there are skills is more important in digital age such as, Presentation, Agility, Digital information, Analysis

c. Adapting Audit Methodology: the audit methodology will need to change in their ways of work for instance:

a- Data Sharing: tools such as Microsoft SharePoint allows documents to be shared in virtual presentation and stored in the cloud

b- Analysis: more analysis will be needed not just financial data

c- Delivery: use PowerPoint and other digital tools to present and communicate the audit result.

3-The Digital Transformation is reducing the cost

Finally, the profession should leverage their strategic ways and methods of work to be adapted for the new generation of technology otherwise they face a problem of how to justify their cost.

\section{References}

[1] JBettim Nathanael and Gerrit Sarens., (2021)," Understanding the internal audit function in a digitalized business environment", Journal of Accounting \& Organizational Change Vol. 17 No. 2, 2021 pp. 197-216.

https://www.emerald.com/insight/1832-5912.htm

[2] -Chartered Institute of Internal Audit, "Impact of Digestion on the Internal Audit Activity", Sept 2020, https://www.iia.org.uk > resources, www.digitalworkplacegroup.com

[3] L Portzenheim, (2019). "The impact of digital transformation on the internal audit process and practices"

https://dial.uclouvain.be > ucl > object > thesis: 20494

[4] Liere-Netheler, K., Packmohr, S., Vogelsang, K.,(2018). "Drivers of Digital Transformation in Manufacturing", Proceedings of the 51st Hawaii 
International Conference on System Sciences, Waikoloa Beach, HI, 3926-3935.

https://muep.mau.se/handle/2043/27162

https://doi.org/10.24251/HICSS.2018.493

[5] Nambisan, S., Wright, M., \& Feldman, M. (2019). The digital transformation of innovation and entrepreneurship: Progress, challenges and key themes. Research Policy, 48(8), 103773

Journal homepage: www.elsevier.com/locate/respo

[6] -Nayar, K.B. and Kumar, V. (2018) 'Cost benefit analysis of cloud computing in education', Int. J. Business Information Systems, Vol. 27, No. 2, pp.205-221.

https://www.researchgate.net/publication/322321070 _Cost_benefit_analysis_of_cloud_computing_in_edu cation

[7] -PWC," Transforming Internal Audit to drive digital value", www.pwc.com/sg

[8] -Internal Audit Foundation and Audit Board,(2021), "Internal Audit's Digital Transformation Imperative: Advances Amid Crisis", the Internal Audit Foundation, theiia.org/Foundation

[9] Radwan, H., (1995), The Control Framework of the Accounting Data for the electronic Processing Purposes Applied in The Financial Management of the Canal harbor and Great Projects Co.", Accounting, Auditing Department, Faculty of Commerce, Suez Canal University.

[10] Fernando Koch, Marcos D. Assun, c a ao, Marco A. S. Netto,(2012)" A Cost Analysis of Cloud Computing for Education", Economics of Grids, Clouds, Systems, and Services 9th International Conference, Berlin, Germany, November 27-28.

https://www.researchgate.net/publication/262332846

[11] -IDC (2018), "The role of Cloud Computing in Digital Transformation"

https://www.euronovate.com/the-role-of-cloudcomputing-in-digital-transformation/

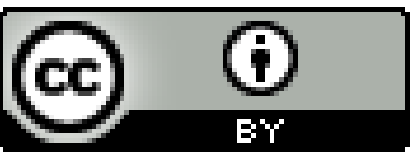

